\title{
MOTIVASI DAN KARAKTERISTIK SOSIAL EKONOMI RUMAH TANGGA PENANAM POHON PENGHASIL KAYU PERTUKANGAN : KASUS TRADISI MENANAM KAYU BAWANG (Disoxylum molliscimum BL) OLEH MASYARAKAT KABUPATEN BENGKULU UTARA, BENGKULU (Motivation and Household Characteristics of Timber Tree Grower:
} The Case of the traditional plantation of Kayu Bawang (Disoxylum molliscimum Bl) by People at North Bengkulu, Bengkulu Province)

\author{
Oleh/By : \\ Edwin Martin dan Fidelia Balle Galle \\ Balai Penelitian Kehutanan Palembang \\ Jl. Kol. H. Burlian Km 6,5 Kotak Pos 179 Puntikayu, Palembang \\ Telp./Fax, (0711) 414864 \\ e-mail: abinuha1976@yahoo.co,id
}

Naskah diterima : 20 Maret 2009 / Edit terakhir : 17 April 2009

\begin{abstract}
Most of the development forestry program of last decade based on timber tree species as comodity, meanwhile there is scant information on how people could accepted those plants on their own farmland traditionally. An understanding of motivation and household characteristics of traditional timber tree grower is important in expanding and improving the practice. This paper seeks to analyze the relationship between grade of motivation and household characteristics of 'kayu bawang' grower at North Bengkulu, Bengkulu Province. Chi-square analyses were applied to explore the associations between household characterictics and grade of motivation on planting timber tree. The analyses demonstrate two of important conclusions: (i) people of North Bengkulu have medium to high motivation on grow of timber tree; driven by economic factor such as comercial orientation and stock. for the future timber consumption, felt satisfied on current timber business, and were going to maintain the tree, (ii) high motivation on grow timber tree actually associated with farm size and formal education of head of household; large of farm size could support mixed plantation and lower formal education of head of household might influenced his/ her consistency on this traditional activity. As reflection of this finding so thatpeer teaching (farmer to farmer) should be considered as extension effort in various of timber tree based forestry program.
\end{abstract}

Keywords: Household characteristics, kayu bawang, motivation, timber tree

\begin{abstract}
ABSTRAK
Secara umum pelaksanaan Pembangunan kehutanan selama dekade terakhir didasarkan pada komoditi kayu, dan informasi yang diketahui tentang bagaimana masyarakat dapat menerima jenis-jenis tersebut untuk ditanam secara tradisional sangat sedikit. Pengetahuan tentang motivasi dan ciri-ciri rumah tangga terhadap pertumbuhan jenis tradisional tersebut penting dalam pengembangannya dan penyempurnaan dalam pelaksanaannya. Tulisan ini bertujuan untuk mengetahui hubungan motivasi dengan karakteristik rumah tangga petani kayu bawang di kabupaten Bengkulu Utara, Provinsi Bengkulu. Analisa data menggunakan metode chi-square untuk melihat hubungan antara karakteristik rumah tangga dengan tingkat motivasi penanaman pohon. Hasil analisis menunjukkan bahwa masyarakat Kabupaten Bengkulu Utara mempunyai motivasi sedang sampai tinggi untuk menanam
\end{abstract}


pohon; yang didorong oleh faktor ekonomi seperti kebutuhan konsumsi dan untuk persediaan kayu untuk kebutuhan di masa mendatang, perasaan puas terhadap usaha perkayuan sekarang dan keinginan untuk mempertahankan pohon, ii) motivasi yang tinggi untuk menanam pohon berhubungan dengan ukuran luas lahan petani; petani yang mempunyai lahan yang luas akan mendukung tanaman campuran dan tingkat pendidikan yang rendah dari kepala rumah tangga petani akan mempengaruhi kekonsistenan dalam pelaksanaan kegiatan. Berdasarkan hasil penelitian ini pembelajaran antar petani perlu dipertimbangkan sebagai usaha penyuluhan dalam pengembangan tanaman kayu.

Kata kunci : Karakteristik rumah tangga, kayu bawang, motivasi dan pohon

\section{PENDAHULUAN}

Hutan rakyat salah satu alternatif pemenuhan kebutuhan kayu di tingkat lokal, regional dan nasional. Skema Hutan Rakyat digunakan oleh pemerintah dalam program rehabilitasi lahan dan pembangunan hutan tanaman. Pembangunan hutan rakyat umumnya mengadaptasi keberhasilan beberapa kelompok masyarakat tradisional membangun kebun hutan (forest garden) pada lahan milik.

Hutan rakyat yang sering menjadi acuan dalam pengembangan perhutanan sosial baik dari sisi keilmuan maupun untuk kepentingan praktis, adalah hutan damar mata kucing di Krui Lampung Barat (Torquebiau, 1984; de Foresta et al., 2000; Wijayanto 2002; Kartasubrata, 2003), hutan kayu manis di Sumatera Barat (Michon et al., 1986; Kartasubrata, 2003), hutan kemenyan di Tapanuli Utara (Dede, 1998), dan jenis karet yang membentuk hutan (Gouyon et al., 1993; Suyanto et al., 2001). Karakteristik umum model hutan rakyat berpola agroforestry berbasis jenis penghasil bukan kayu. Keberhasilan masyarakat mengembangkan hutan rakyat berbasis jenis penghasil kayu pertukangan belum banyak diungkap. Komposisi jenis tanaman penghasil kayu lebih dibutuhkan dan banyak digunakan dibanding jenis pohon serbaguna dalam program pembangunan yang difasilitasi pemerintah.

Saat ini belum banyak laporan penelitian yang menganalisis kearifan tradisional masyarakat dalam menanam jenis pohon penghasil kayu pertukangan pada lahan milik. Martin et al. (2003) memperkenalkan tradisi menanam jenis bambang (Madbuca aspera) oleh masyarakat Lintang Di Kabupaten Lahat Sumatera Selatan. Anwar et al. (1999) memperkenalkan dan menguraikan teknik silvikultur hutan rakyat kayu bawang (Disoxylum molliscimum Bl.) sebagai tanaman budidaya masyarakat Kabupaten Bengkulu Utara, Bengkulu. Kedua kelompok peneliti ini tidak menjelaskan alasan sosial ekonomi dan karakteristik rumah tangga penanam pohon penghasil kayu pertukangan tersebut. Karakteristik ini merupakan obyek analisis yang paling diperhatikan dalam literatur internasional mengenai kebun pekarangan dan agroforestry (Montambault dan Alavalapati, 2005). Keputusan menanam suatu jenis pohon di areal usaha tani dilakukan dalam unit rumah tangga yang dipimpin oleh seorang kepala rumah tangga (David, 1997; Sood dan Mitchell, 2004).

Sejak tahun 2003, jenis bambang dan bawang digunakan secara luas di luar habitat tradisionalnya dalam program rehabilitasi hutan dan lahan serta pengembangan hutan rakyat. Martin et al. (2002) menemukan indikasi ketidakberhasilan program rehabilitasi hutan dan lahan serta pengembangan hutan rakyat dengan jenis tanaman penghasil kayu pertukangan. Masyarakat yang tidak memiliki tradisi menanam pohon penghasil kayu umumnya enggan menanami lahan miliknya dengan komoditas investasi jangka panjang. Oleh karena itu, perlu dipelajari pada masyarakat yang telah mempunyai tradisi kuat dalam membudidayakan 
komoditas penghasil kayu, apakah terdapat hubungan antara karakteristik sosial ekonomi rumah tangga penanam dengan keinginan (motivasi) menanam pohon? Pertanyaan tersebut hendak dijawab melalui studi kasus pada masyarakat di Kabupaten Bengkulu Utara yang secara tradisional telah membudidayakan kayu bawang.

Penelitian ini bertujuan untuk mengetahui keterkaitan antara motivasi menanam kayu bawang dengan karakteristik sosial ekonomi rumah tangga penanamnya. Hasil penelitian diharapkan dapat menjadi dasar dalam mengembangkan pohon penghasil kayu pertukangan pada areal hutan rakyat yang lebih luas.

\section{METODOLOGI PENELITIAN}

\section{A. Kerangka Kerja Teoritis}

Dalam Kamus Besar Bahasa Indonesia motivasi didefinisikan sebagai dorongan yang timbul pada diri seseorang secara sadar atau tidak sadar untuk melakukan suatu tindakan dengan tujuan tertentu. Berdasarkan sifatnya, dikenal motivasi ekstrinsik, yaitu dorongan yang datang dari luar diri seseorang, dan motivasi intrinsik, yaitu dorongan atau keinginan yang tidak perlu disertai perangsang dari luar. Motivasi ekstrinsik adalah keinginan seseorang misalnya setelah melihat keberhasilan masyarakat lain dalam usaha budidaya tanaman. Motivasi intrinsik adalah keinginan seseorang untuk meningkatkan pendapatan dengan pengoptimalan pemanfaatan lahan dan investasi modal yang dimiliki. Motivasi seseorang dalam mengusahakan sesuatu dengan karakteristik pribadi.

Pendidikan dan umur merupakan variabel pendekatan yang paling banyak digunakan dalam penelitian preferensi rumah tangga dalam sistem agroforestry (Pattanayak et al., 2003). Aset dan sumberdaya tersedia yang inheren dengan rumah tangga penanam pohon adalah luas kepemilikan lahan dan pendapatan. Keputusan petani menanam pohon pada lahan milik didasarkan kepada kepentingan ekonomi dibanding ekologi (Salam et al., 2000). Motif ekonomi berperan penting dibanding alasan ekologis ketika petani membentuk agroforest multistrata (Torquebiau dan Penot, 2006), dan menanami lahan alang-alang dengan tanaman berkayu (Predo, 2003). Kerangka teoritis ini mendasari analisis dan penyusunan variabel karakteristik responden dan tingkat motivasi.

\section{B. Waktu dan Tempat Penelitian}

Penelitian ini dilaksanakan pada Bulan Oktober hingga Desember 2005 di Kecamatan Air Besi dan Kecamatan Air Napal dalam wilayah Kabupaten Bengkulu Utara, Provinsi Bengkulu. Kedua Kecamatan tersebut secara geografis bertetangga.

\section{Metode Pengumpulan Data}

Penentuan lokasi ditentukan secara multistage purposive sampling. Kabupaten Bengkulu Utara karena masyarakatnya membudidayakan kayu bawang sebagai penghasil kayu pertukangan (Anwar et al., 1999). Berdasarkan hasil diskusi dengan aparat (termasuk penyuluh) Dinas Kehutanan Bengkulu Utara dipilih Kecamatan Air Besi, Kecamatan Air Napal. Di Kecamatan Air Besi ditentukan tiga desa contoh, yaitu Desa Datar Macang, Dusun Curup dan Genting Perangkap, di Kecamatan Air Napal dipilih satu desa, yaitu Lubuk Semantung. 
Responden penelitian adalah kepala rumah tangga yang diasumsikan sebagai penentu keputusan termasuk dalam pemilihan jenis untuk ditanam pada lahan usaha tani. Umur dan tingkat pendidikan representasi karakteristik kepala rumah tangga, serta pendapatan dan luas lahan milik dianggap mewakili karakteristik unit rumah tangga.

Penentuan responden dilakukan secara acak sederhana terhadap populasi rumah tangga yang mempunyai paling sedikit 20 pohon kayu bawang di lahan miliknya. Jumlah responden yang bersedia dan berhasil diwawancarai dari keempat desa sebanyak 114 orang.

Berdasarkan sumbernya, penelitian menggunakan data primer dan data sekunder. Data primer dikumpulkan dari hasil wawancara terhadap responden dan aparat Dinas Kehutanan Kabupaten Bengkulu Utara yang dilengkapi observasi lapang tegakan/kebun milik masyarakat. Data sekunder dikumpulkan dari instansi terkait yang relevan dan mendukung keperluan analisis data penelitian.

\section{Analisis Data}

Tingkat motivasi penanam kayu bawang ditentukan jawaban atas tiga pertanyaan kunci, yaitu tujuan menanam, persepsi budidaya, dan rencana selanjutnya budidaya kayu bawang. Jawaban responden atas pertanyaan tujuan menanam dikelompokkan dan diberi skor menjadi alasan komersial/investasi (3), pemenuhan kebutuhan bahan bangunan (2), dan tidak memiliki tujuan yang jelas (1). Perpsepsi responden atas usaha budidaya sangat menguntungkan (3), menguntungkan (2), tidak memberi manfaat (1). Bagi pertanyaan rencana selanjutnya budidaya akan terus mengembangkan usaha (3), hanya akan terus mengembangkan jika keadaan memungkinkan (2), dan akan mengganti dengan usaha komoditas lain (1). Jawaban responden dikategorikan mempunyai motivasi tinggi bila total skor lebih atau sama dengan 8 , sedang skor 6 dan 7, serta rendah skor kurang dari 6 .

Keterkaitan variabel-variabel karakteristik rumah tangga yang menanam kayu bawang dengan tingkat motivasinģa dianalisis dengan uji Chi Square $\left(^{2}\right)$ (Daniel, 1989), dengan rumus:

$$
\chi^{2}=\sum_{i=1} \sum_{j=1}\left(O_{i j}-E_{i j}\right)^{2} / E_{i j}
$$

$$
\begin{aligned}
& \sum_{i=1}^{B} \sum_{j=1}^{K}=\text { Jumlah semua baris (B) dan semua kolom }(\mathrm{K}) \\
& \begin{aligned}
O_{i j} \quad & \text { Jumlah observasi untuk kasus dikategorikan dalam baris ke-i kolom ke- } j \\
E_{i j} \quad & \text { Banyaknya kasus yang diharapkan di bawah Ho untuk dikategorikan dalam baris ke-i } \\
& \text { pada kolom ke- } j
\end{aligned}
\end{aligned}
$$

$$
E_{i j}=\left(n_{i 0} \times n_{0 j}\right) / n
$$

dimana:

$n_{i}=$ Jumlah pengamatan pada baris ke-i

$n_{j}=$ Jumlah pengamatan pada kolom ke-j

$n=$ Jumlah total dari pengamatan 
Hipotesis nol (Ho) menyatakan bahwa antara variabel karakteristik rumah tangga dengan tingkat motivasi tidak saling berkaitan atau saling bebas. Hipotesis nol ditolak apabila nilai statistik uji $\chi^{2}$ hasil perhitungan lebih besar daripada nilai $\chi_{1-\sigma}^{2}$ dalam tabel untuk derajat bebas $(b-1)(k-1)$ pada taraf nyata $\sigma$.

Derajat keterkaitan antara variabel bebas dengan variabel tak bebas yang nyata, digunakan koefisien kontingensi (C) (Sudjana, 1985) dengan rumus sebagai berikut:

$$
C=\sqrt{\frac{\chi^{2}}{\chi^{2}+n}}
$$

$$
\begin{aligned}
& \text { dimana: } \\
& \begin{array}{l}
\mathrm{C}=\text { Koefisien kontingensi } \\
\chi^{2}=\text { Nilai Chi Square hasil perhitungan } \\
\mathrm{n}=\text { Jumlah contoh }
\end{array}
\end{aligned}
$$

Untuk dapat menilai derajat asosiasi antara variabel bebas dengan variabel tidak bebas, maka harga $\mathrm{C}$ dibandingkan dengan koefisien kontangensi maksimum $\left(\mathrm{C}_{\text {maks }}\right)$ yang bisa terjadi. Makin dekat harga $\mathrm{C}$ kepada $\mathrm{C}_{\text {maks }}$, makin besar derajat asosiasi antara variabel bebas dengan variabel tidak bebas. Harga $\mathrm{C}_{\text {maks }}$ dihitung dengan rumus:

$$
C_{\text {maks }}=\sqrt{\frac{m-1}{m}}
$$

dimana:

$\mathrm{C}_{\text {maks }}=$ Koefisien kontingensi maksimum

$\mathrm{m}=$ Harga minimum antara B dan K (yakni minimum antara banyaknya baris dan kolom)

\section{GAMBARAN UMUM LOKASI}

\section{A. Biofisik}

Secara geografis Kabupaten Bengkulu Utara terletak pada posisi $101^{\circ} 31^{\prime}$ sampai $102^{\circ}$ $8^{\prime}$ Bujur Timur serta $2^{\circ} 15$ sampai $4^{\circ}$ Lintang Selatan di antara gugusan Pegunungan Bukit Barisan hingga Samudera Indonesia dengan garis pantai sepanjang kurang lebih $300 \mathrm{~km}$. Dataran rendah dengan ketinggian 10 - $150 \mathrm{~m}$ dari permukaan laut (dpl) terdapat di bagian Pantai Barat dari Selatan ke Utara. Sedangkan di bagian Timur merupakan daerah berbukit dengan ketinggian rata-rata $541 \mathrm{~m}$ dpl. Kabupaten Bengkulu Utara berbatasan dengan Provinsi Sumatera Barat di sebelah Utara, Kabupaten Bengkulu Selatan dan Kota Bengkulu di sebelah selatan, Provinsi Jambi dan Kabupaten Rejang Lebong di sebelah timur, Samudera Indonesia di sebelah barat.

Kabupaten Bengkulu Utara memiliki bentuk lahan yang relatif bergelombang dengan kemiringan lahan datar hanya sebesar $27,91 \%$ dan selebihnya $72,09 \%$ merupakan lahan dengan kemiringan 15 - 40\% ke atas dengan luas mencapai 690.965 ha. Jenis tanahnya sebagian besar merupakan jenis latosol, asosiasi latosol merah kuning, dan podsolik merah kuning. Pola penggunaan lahan umumnya didominasi oleh lahan-lahan pertanian seperti 
sawah, pertanian, lahan kering dan perkebunan.

Kabupaten Bengkulu Utara merupakan daerah dengan curah hujan rata-rata bulanan $270 \mathrm{~mm}$ dan tahunan $2.500-4.000 \mathrm{~mm}$. Suhu rata-rata antara $22^{\circ} \mathrm{C}$ sampai dengan $32^{\circ} \mathrm{C}$, dengan suhu tertinggi terjadi pada bulan Juni dan terendah terjadi pada bulan Juli. Berdasarkan klasifikasi iklim menurut Schmidt dan Ferguson, daerah ini tergolong tipe iklim C dengan tingkat kelembaban 60\% - 70\%. Jumlah bulan basah 3,6 dan jumlah bulan kering 3,2.

\section{b. Sosial Ekonomi}

Penduduk Kabupaten Bengkulu Utara berdasarkan hasil Pendaftaran Pemilih dan Pendataan Penduduk Berkelanjutan (P4B) tahun 2004 sebanyak 345.135 jiwa. Kepadatan penduduk sebesar 62,20 jiwa/ $\mathrm{km}^{2}$ (BAPPEDA dan BPS Bengkulu Utara, 2004).

Penduduk Kabupaten Bengkulu Utara terdiri dari multi etnis, disamping penduduk asli. Hal ini merupakan konsekuensi dari keberadaan Kabupaten Bengkulu Utara sebagai salah satu daerah tujuan transmigrasi di Indonesia. Beberapa suku yang mendominasi diantaranya adalah suku Jawa, Bali, Rejang dan Muko-Muko.

Sebagian besar penduduk Bengkulu Utara bekerja pada lapangan usaha pertanian, yakni 78,33\%. Selanjutnya di bidang jasa sebanyak 8,96\% dan perdagangan sebanyak 6,05\%, sisanya tersebar dalam lapangan usaha pertambangan dan galian, industri dan lainya.

Penduduk Kabupaten Bengkulu Utara yang berusia 10 tahun ke atas berpendidikan tamat SD sebanyak 130.023 jiwa, tidak tamat SD sebanyak 106.906 jiwa, berpendidikan SLTP sebanyak 52.112 jiwa dan SLTA sebanyak 36.092 jiwa, dan penduduk yang menikmati pendidikan tinggi sebanyak 8.805 jiwa.

\section{HASIL DAN PEMBAHASAN}

\section{A. Budidaya Kayu Bawang oleh Masyarakat}

Kayu bawang bagi masyarakat di Kabupaten Bengkulu Utara merupakan tanaman tradisional warisan orang tua mereka dan mulai sengaja ditanam pada dekade tahun 195060 an di kebun atau bekas ladang. Kayu ini banyak ditanam karena mempunyai mutu baik dan budidayanya relatif mudah.

Tumbuh baik di wilayah yang memiliki curah hujan tahunan sekitar $3.500 \mathrm{~mm}$ dengan curah hujan bulanan antara 150 - $500 \mathrm{~mm}$, pada ketinggian $0-1000 \mathrm{~m} \mathrm{dpl}$.

Umumnya tumbuh pada semak belukar dekat pemukiman. Di Bengkulu Utara hanya ditemukan di daerah yang tersentuh aktivitas manusia (bekas ladang, kebun atau tegalan). Anwar et al. (1999) menduga semua tanaman yang ada merupakan hasil budidaya (ditanam secara sengaja). Pohonnya umumnya menempati strata paling atas dan merupakan pohon dominan. Jenis tanaman lain yang ditemukan adalah kopi, karet, durian, kelapa, mangga, aren, dan pisang (Gambar 2).

Tinggi pohon mencapai $30 \mathrm{~m}$ dengan diameter $75 \mathrm{~cm}$. Bentuk batang silindris agak lengkung. Tajuk tanaman muda berbentuk bulat lonjong, dan pohon tua tidak beraturan/ melebar. Tumbuh pada jenis tanah alluvial dan podsolik merah kuning.

Warna kayu kuning kemerah-merahan dengan sedikit corak coklat, mudah diolah, memiliki aroma bawang dan dilaporkan tahan serangan rayap/bubuk. Sifat menarik untuk dibudidayakan dan dimanfaatkan sebagai kayu konstruksi rumah dan konstruksi lain 


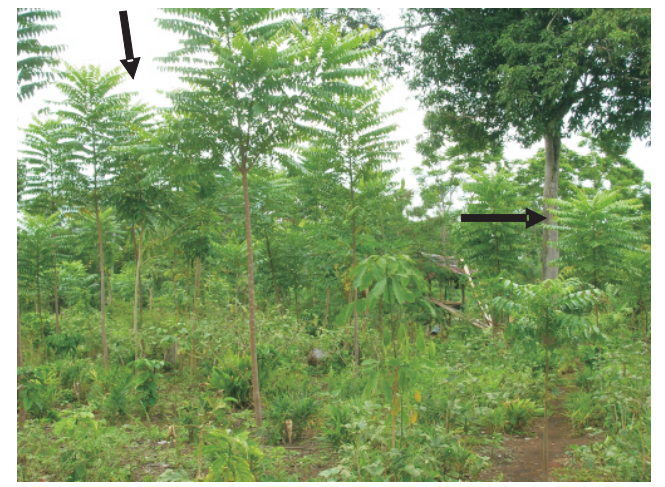

Gambar (Figure) 2. Pohon kayu bawang muda di antara tanaman lain dalam ladang masyarakat Bengkulu Utara (The young bawang muda trees between other species in farming land in North Bengkulu)

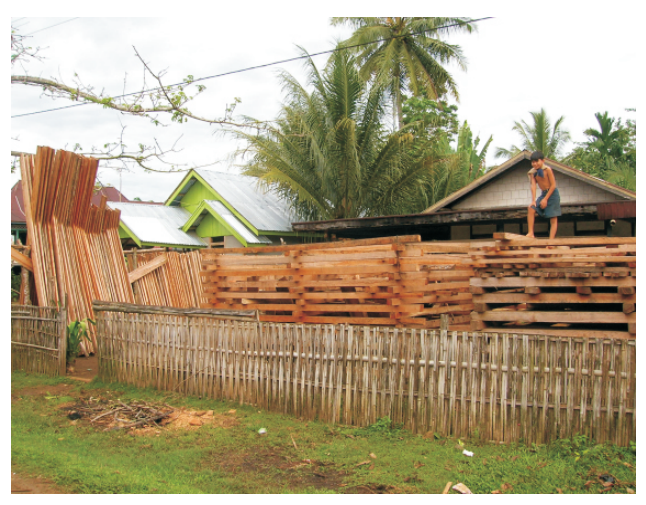

Gambar (Figure) 3. Tumpukan kayu hasil panen pohon kayu bawang; diperjual-belikan atau untuk pemenuhan kebutuhan rumah tangga sendiri (The bulk of kayu bawang trees for selling or self consumption)

Dinas Kehutanan Bengkulu Utara (2004) memproyeksikan bahwa kayu bawang dapat dipanen pada umur 15 - 20 tahun dengan hasil kayu per pohon 1,10 $\mathrm{m}^{3}$. Harga satu $\mathrm{m}^{3} \mathrm{di}$ tingkal regional Kabupaten Bengkulu Utara pada Bulan Oktober 2005 antara Rp 750.000,hingga Rp 800.000,-.

\section{B. Karakteristik Responden}

Karakteristik responden dalam penelitian ini meliputi umur, pendidikan, pendapatan per bulan, dan luas lahan milik (Tabel 1). Umur responden diklasifikasi menjadi dua kelompok yaitu termasuk ke dalam angkatan kerja muda ( $<40$ tahun) dan angkatan kerja tua (40 tahun). Hasil penelitian menunjukkan bahwa 58,77\% responden penanam kayu termasuk ke dalam golongan angkatan kerja muda, sisanya angkatan kerja tua. 
Tabe11. Karakteristik 114 responden rumah tangga yang membudidayakan kayu bawang di Kecamatan Air Besi dan Air Napal Kabupaten Bengkulu Utara, Bengkulu

Table 1. The characteristics of 114 respondents of the growth of kayu bawang in subdistrict Air Besi and Air Napak in North Bengkulu district

\begin{tabular}{|c|c|c|c|}
\hline $\begin{array}{l}\text { Karakteristik } \\
\text { responden } \\
\text { (Renspondent } \\
\text { characteristicts) }\end{array}$ & $\begin{array}{c}\text { Klasifikasi } \\
\text { (Classification) }\end{array}$ & $\begin{array}{l}\text { Jumlah } \\
\text { (Total) }\end{array}$ & $\begin{array}{l}\text { Persentase } \\
\text { (Percentage) }\end{array}$ \\
\hline \multirow{6}{*}{$\begin{array}{l}\text { Umur } \\
(A g e)\end{array}$} & Angkatan kerja muda & & \\
\hline & (Young labour) & 67 & 58,8 \\
\hline & $(<40$ tahun $)$ & & \\
\hline & Angkatan kerja tua & & \\
\hline & (Old labour ) & 47 & 41,2 \\
\hline & ( $\geq 40$ tahun) & & \\
\hline \multirow{3}{*}{$\begin{array}{l}\text { Pendidikan } \\
\text { (Education) }\end{array}$} & Rendah (Low) & 73 & 64,0 \\
\hline & Menengah (Medium) & 36 & 31,6 \\
\hline & Tinggi (High) & 5 & 4,4 \\
\hline \multirow{4}{*}{$\begin{array}{c}\text { Pendapatan } \\
\text { Per bulan } \\
\text { (Income/ } \\
\text { month) }\end{array}$} & $<$ Rp. $500.000,-$ & 27 & 23,7 \\
\hline & Rp. 500.000 s.d. Rp. 1.000 .000 & 48 & 42,1 \\
\hline & $>$ Rp. 1.000 .000 s.d. 2.000 .000 & 28 & 24,6 \\
\hline & $>$ Rp. 2.000 .000 & 11 & 9,6 \\
\hline \multirow{3}{*}{$\begin{array}{l}\text { Luas lahan milik } \\
\text { (Area of landhold) }\end{array}$} & $<1$ ha & 27 & 23,7 \\
\hline & $1-2$ ha & 55 & 48,2 \\
\hline & $>2 \mathrm{ha}$ & 32 & 28,1 \\
\hline
\end{tabular}

Sebagian besar responden (64,04\%) tergolong berpendidikan rendah, tidak pernah menempuh pendidikan dasar atau hanya sampai sekolah dasar (SD). Di sisi lain, sebanyak 4,38 $\%$ penanam kayu bawang ini telah menyelesaikan pendidikan tinggi. Ini berarti penanam kayu bawang menyebar pada semua tingkatan pendidikan di masyarakat, tidak hanya di tanam oleh kelompok masyarakat yang berpendidikan rendah.

Responden penanam kayu bawang ternyata lebih banyak pada klasifikasi berpendapatan cukup (antara Rp. 500.000,- sampai dengan Rp. 2.000.000,-), atau di atas rata-rata upah minimum regional (UMR) Provinsi Bengkulu Tahun 2006 sebesar Rp 512.000,-. Sebagai catatan bahwa sebanyak 88,59\% responden berprofesi sebagai petani, khususnya petani karet dan kopi. Responden umumnya mengatakan bahwa pendapatannya meningkat semenjak mereka dapat memperdagangkan getah (lateks) tanaman karet dalam dua tahun terakhir ini. 
Luas lahan milik yang diusahakan oleh responden penanam kayu bawang umumnya lebih dari satu ha. Lahan usaha ini ditanami dengan komoditas tanaman keras seperti karet, kopi, durian, dan kayu bawang. Introduksi kayu bawang ke areal budidaya biasanya dilakukan pada tahun-tahun pertama (tahun 1 dan 2) setelah pembukaan lahan baru, sehingga terbentuk keragaman pola agroforestri. Lahan milik yang relatif dekat dengan pemukiman cenderung diusahakan dengan jenis tanaman industri, seperti karet dan kopi, sementara kayu bawang merupakan tanaman selingan yang terpencar atau sebagai batas kepemilikan. Lahan milik yang relatif jauh biasanya lebih didominasi tegakan kayu bawang atau bercampur di antara tanaman industri.

\section{Keterkaitan antara karakteristik rumah tangga dan tingkat motivasi}

Sebagian besar responden menyatakan bahwa tujuan menanam kayu bawang adalah untuk penyiapan kebutuhan bahan bangunan pada masa mendatang $(84,21 \%)$, hanya $14,91 \%$ responden yang menanam kayu bawang dengan tujuan investasi atau komersial. Persepsi responden mengenai usaha pembudidayaan kayu bawang di lahan milik, 91,23\% menyatakan menguntungkan, 6\% sangat menguntungkan, dan 2,6\% ragu-ragu. Untuk pertanyaan "rencana selanjutnya terhadap usaha pembudidayaan kayu bawang", sebanyak 69,29 \% responden menyatakan akan terus memelihara dan menanam kayu bawang, 28,07\% responden akan melihat kondisi lingkungan atau tergantung kebutuhan, dan 2,6\% responden yang berniat mengganti kayu bawang dengan peruntukan lain. Ketiga sisi pendapat responden menghasilkan pemahaman tingkat motivasi mereka dalam menanam kayu bawang (Gambar 4).

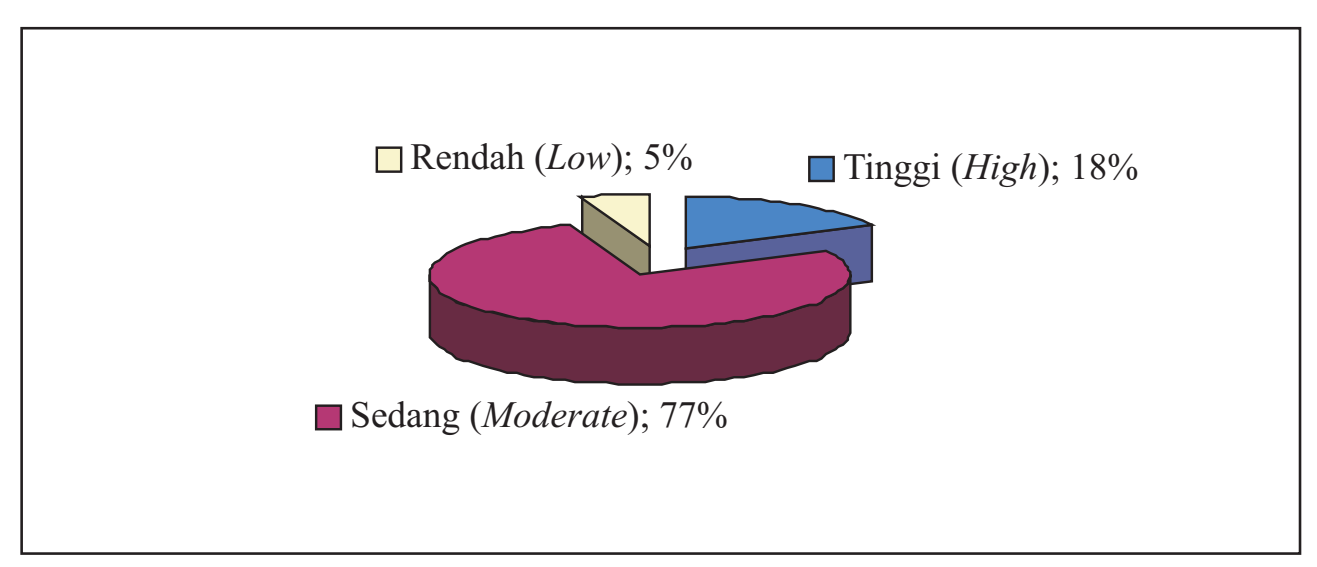

Gambar 4. Tingkat motivasi 114 rumah tangga penanam pohon kayu bawang di Kabupaten Bengkulu Utara

Figure 4. The motivation level of 114 growerkayu bawang household in North Bengkulu 


\section{C.1. Umur dan tingkat motivasi}

Hipotesis yang diuji adalah (Ho) umur responden tidak berkaitan dalam metode dengan tingkat motivasi menanam kayu bawang. Tabel 2 merupakan tabulasi silang antara klasifikasi umur responden dengan motivasi dalam menanam kayu bawang.

Tabel2. Keterkaitan antara umur responden dengan tingkat motivasi dalam menanam kayu bawang

Table 2. The linkage between respondents with motivation level in plantation of kayu bawang

\begin{tabular}{|c|c|c|c|c|c|c|}
\hline \multirow{3}{*}{$\begin{array}{c}\text { Motivasi } \\
\text { (Motivation) }\end{array}$} & \multicolumn{4}{|c|}{ Umur $(A g e)$} & \multirow{2}{*}{\multicolumn{2}{|c|}{$\begin{array}{c}\text { Jumlah } \\
\text { (Total) }\end{array}$}} \\
\hline & \multicolumn{2}{|c|}{$\begin{array}{c}\text { Angkatan kerja muda } \\
\text { (Young labour) } \\
\text { (15-40 tahun) }\end{array}$} & \multicolumn{2}{|c|}{$\begin{array}{c}\text { Angkatan kerja tua } \\
\text { (Old labour }) \\
\text { (> } 40 \text { tahun })\end{array}$} & & \\
\hline & $\mathrm{N}$ & $\%$ & $\mathrm{~N}$ & $\%$ & $\mathrm{~N}$ & $\%$ \\
\hline Tinggi (High) & 9 & 13,43 & 11 & 23,40 & 20 & 17.45 \\
\hline Sedang (Medium) & 53 & 79,10 & 35 & 74,47 & 88 & 77,19 \\
\hline Rendah (Low) & 5 & 7,46 & 1 & 2,13 & 6 & 5,26 \\
\hline Jumlah (Total) & 67 & 100 & 47 & 100 & 114 & 100 \\
\hline
\end{tabular}

Hasil analisis chi square $\left(\chi^{2}\right)$ terhadap Tabel 2 sebesar 5,45. Dibandingkan dengan nilai $\chi^{2}$ tabel pada derajat bebas 2 dengan taraf nyata $99 \%$ sebesar 9,21, maka $\chi^{2}$ hitung lebih kecil dari $\chi^{2}$ tabel atau hipotesis nol diterima. Artinya, umur responden tidak berkaitan dengan motivasi dalam menanam kayu bawang.

Hasil penelitian yang menyatakan tidak adanya kaitan antara umur responden dengan tingkat motivasi menanam kayu bawang berarti bahwa pada semua level angkatan kerja masyarakat memiliki tingkat motivasi yang sama dalam menanam kayu bawang. Angkatan kerja muda tetap mempertahankan tradisi menanam kayu bawang pada lahan milik meskipun struktur luasannya mulai menyempit dibanding kepemilikan orang tua mereka dulu. Mereka menanam kayu bawang sebagai tanaman pagar atau terpencar tidak berpola dalam unit lahan. Ini terjadi karena mereka telah merasakan arti penting dari penanaman kayu bawang.

Manfaat budidaya kayu bawang oleh orang tua dirasakan nyata oleh generasi muda di Kabupaten Bengkulu Utara. Masyarakat dapat membangun rumah dengan biaya lebih murah karena menggunakan kayu milik sendiri. Mereka juga dapat menikmati hasil penjualan kayu dalam bentuk pohon berdiri atau papan, dengan harga yang dianggap cukup memuaskan. Bukti ini sebagai pendorong utama generasi muda di tetap mempertahankan tradisi menanam kayu bawang.

Motivasi tinggi dalam menanam pohon kayu bawang juga dimiliki oleh angkatan kerja tua karena merupakan strategi investasi pada saat tenaga menjadi pembatas. Dalam menanam tidak memerlukan tenaga kerja intensif. Orang tua tidak mungkin bekerja penuh sebagaimana dipersyaratkan dalan usahatani tanaman semusim dan tanaman industri (karet, kakao, kopi). 
Hasil penelitian Ruf et al. (2005) tentang inovasi peremajaan kopi di Kabupaten Lahat dan Kepahiang, tetangga dekat Kabupaten Bengkulu Utara, menunjukkan bahwa umur petani merupakan faktor yang memengaruhi peremajaan kopi. Peremajaan kopi banyak dilakukan petani muda yang memiliki kesiapan tenaga dan tuntutan intensifikasi ketika memperoleh informasi tentang komoditas lain yang lebih menjanjikan. Petani berumur tua cenderung melakukan diversifikasi dengan jenis kemiri di antara tanaman kopi karena tenaganya sudah berkurang. Ini berarti tindakan usahatani, termasuk menanam kayu petukangan, oleh angkatan kerja muda dipengaruhi oleh aspek positif tentang untung dan rugi, sementara bagi angkatan kerja tua mengedepankan nilai sosial kehidupan (kenyamanan, keamanan, dan lainnya).

\section{C.2. Luas lahan milik dan tingkat motivasi}

Hipotesis yang diuji adalah (Ho) luas lahan responden tidak berkaitan dengan motivasi menanam kayu bawang. Tabel 3 merupakan tabulasi silang antara luas lahan responden dengan motivasi mereka dalam menanam kayu bawang.

\section{Tabel3. Keterkaitan antara luas lahan garapan responden dengan tingkat motivasi dalam menanam kayu bawang}

Table 3. The linkage between landuse and motivation level inplantation of kayu bawang

\begin{tabular}{|c|c|c|c|c|c|c|c|c|}
\hline \multirow{3}{*}{$\begin{array}{c}\text { Motivasi } \\
\text { (Motivation) }\end{array}$} & \multicolumn{6}{|c|}{ Luas lahan garapan (Area of cultivated land } & \multirow{2}{*}{\multicolumn{2}{|c|}{$\begin{array}{c}\text { Jumlah } \\
\text { (Total) }\end{array}$}} \\
\hline & \multicolumn{2}{|c|}{$<1$ ha } & \multicolumn{2}{|c|}{$1-2$ ha } & \multicolumn{2}{|c|}{$>2$ ha } & & \\
\hline & $\mathrm{N}$ & $\%$ & $\mathrm{~N}$ & $\%$ & $\mathrm{~N}$ & $\%$ & $\mathrm{~N}$ & $\%$ \\
\hline Tinggi (High) & 3 & 12,5 & 12 & 22,2 & 5 & 13,8 & 20 & 17.45 \\
\hline Sedang (Moderate) & 18 & 75 & 42 & 77,7 & 28 & 77,7 & 88 & 77,19 \\
\hline Rendah (Low) & 3 & 12,5 & 0 & 0 & 3 & 0 & 6 & 5,26 \\
\hline Jumlah (Total) & 24 & 100 & 54 & 100 & 36 & 100 & 114 & 100 \\
\hline
\end{tabular}

Hasil analisis chi square $\left(\chi^{2}\right)$ terhadap Tabel 3 sebesar 369,68. Dibandingkan dengan nilai $\chi^{2}$ tabel pada derajat bebas 4 dengan taraf nyata 99\% sebesar 13,28 maka $\chi^{2}$ hitung lebih besar dari $\chi^{2}$ tabel atau hipotesis nol ditolak. Artinya, luas kepemilikan lahan responden berkaitan dengan motivasi dalam menanam kayu bawang.

Keeratan hubungan antara luas lahan garapan dengan motivasinya dihitung dengan membandingkan koefisien kontangensi (C) dengan koefisien kontangensi yang mungkin terjadi. Nilai koefisiensi kontangensi (C) yang diperoleh 0,874 , sedangkan nilai koefisien kontangensi maksimum (Cmaks) yang mungkin terjadi adalah 0,816. Ini berarti luas lahan garapan dengan motivasi mempunyai hubungan yang sangat erat.

Responden yang memiliki motivasi tinggi adalah yang mempunyai lahan garapan cukup luas (lebih dari $1 \mathrm{ha}$ ). Motivasi tinggi umumnya ditandai dengan tujuan penanaman kayu bawang sebagai investasi, mempunyai persepsi bahwa usaha tersebut sangat menguntungkan, dan memiliki rencana pengembangan usaha. Keberadaan tegakan dengan berbagai kelas umur merupakan bukti motivasi tinggi. 
Kepemilikan lahan yang luas dapat mengatur areal untuk budidaya tanaman semusim, tanaman industri (cash crop), dan kayu bawang. Ini membuat pemilik lahan luas dapat mengusahakan kayu bawang secara komersial. Masyarakat yang lahan garapannya sempit sulit membuat tegakan khusus kayu bawang, karena lebih mengutamakan tanaman semusim dan industri. Pemilik lahan sempit tetap menanam kayu bawang meskipun motivasinya rendah atau sedang. Mereka menanam kayu sebagai tanaman pagar, atau ditanam secara acak, sebagai cadangan bahan bangunan mereka menganggap usaha ini menguntungkan tetapi tidak mempunyai rencana untuk pengembangan dan beberapa diantaranya berniat mengurangi porsi kayu bawang.

Adanya kaitan luas lahan dengan motivasi menanam kayu bawang di Kabupaten Bengkulu Utara sejalan dengan pendapat Brokensha dan Riley (1987) dalam Suharjito et al. (2003), yang menyatakan rumah tangga miskin dengan lahan sempit cenderung menggunakan lahannya untuk tanaman pangan atau tanaman perdagangan daripada tanaman pohonkayu. Brokensha dan Riley menggunakan kata kunci rumah tangga miskin untuk menghubungkan luas lahan dengan keinginan menanam pohon. Pemilik lahan sempit ada mempunyai motivasi tinggi dalam menanam pohon, karena secara ekonomi tidak bergantung kepada sumberdaya lahan itu. Pada Tabel 3 terlihat tiga orang responden yang memiliki lahan sempit tetapi mempunyai motivasi tinggi.

Luas lahan milik dapat dijadikan pertimbangan dalam menentukan petani atau peserta sasaran dalam pengembangan jenis pohon penghasil kayu pertukangan pada program hutan rakyat atau rehabilitasi lainnya. Lahan sempit tetap dapat diintroduksikan pohon penghasil kayu pertukangan tetapi mungkin dalam jumlah yang sedikit atau hanya sebagai pagar pembatas. Jika lahan sempit tersebut bukan sebagai sumber ekonomi keluarga, maka pembuatan tegakan pohon penghasil kayu pertukangan tetap layak dilaksanakan.

\section{C.3. Pendidikan dan tingkat motivasi}

Hipotesis yang diuji adalah (Ho) pendidikan formal tidak berkaitan dengan motivasi menanam kayu bawang. Tabel 4 merupakan tabulasi silang antara tingkat pendidikan responden dengan motivasi menanam kayu bawang. 
Tabel 4. Keterkaitan antara tingkat pendidikan responden dengan tingkat motivasi dalam menanam kayu bawang

Table 4. The linkage between education level and motivation level in kayu bawang plantations

\begin{tabular}{|c|c|c|c|c|c|c|c|c|}
\hline \multirow{3}{*}{$\begin{array}{l}\text { Motivasi } \\
\text { (Motivation) }\end{array}$} & \multicolumn{6}{|c|}{ Tingkat pendidikan (Education level) } & \multirow{2}{*}{\multicolumn{2}{|c|}{$\begin{array}{l}\text { Jumlah } \\
\text { (Total) }\end{array}$}} \\
\hline & \multicolumn{2}{|c|}{$\begin{array}{c}\text { Rendah } \\
\text { (Low) }\end{array}$} & \multicolumn{2}{|c|}{$\begin{array}{c}\text { Menengah } \\
\text { (Medium) }\end{array}$} & \multicolumn{2}{|c|}{$\begin{array}{l}\text { Tinggi } \\
(H i g h)\end{array}$} & & \\
\hline & $\mathrm{N}$ & $\%$ & $\mathrm{~N}$ & $\%$ & $\mathrm{~N}$ & $\%$ & $\mathrm{~N}$ & $\%$ \\
\hline Tinggi (High) & 14 & 19,18 & 6 & 16,67 & 0 & - & 20 & 17,54 \\
\hline Sedang (Moderate) & 54 & 73,97 & 29 & 80,56 & 5 & 100 & 88 & 77,19 \\
\hline Rendah (Low) & 5 & 6,85 & 1 & 2,78 & 0 & - & 6 & 5,26 \\
\hline Jumlah (Total) & 73 & 100 & 36 & 100 & 5 & 100 & 114 & 100 \\
\hline
\end{tabular}

Keterangan (Remarks) : $\mathrm{N}=$ jumlah responden (total respondents)

Hasil analisis chi square $\left(\chi^{2}\right)$ terhadap Tabel 4 sebesar 89,35. Dibandingkan dengan nilai $\chi^{2}$ tabel pada derajat bebas 4 dan taraf nyata $99 \%$ sebesar 13,28 , maka $\chi^{2}$ hitung lebih besar dari $\chi^{2}$ tabel atau hipotesis nol ditolak. Artinya tingkat pendidikan berkaitan dengan motivasi dalam menanam kayu bawang. Nilai koefisiensi kontangensi (C) yang diperoleh 0,663, sedangkan nilai koefisien kontangensi maksimum (Cmaks) yang mungkin terjadi 0,816. Ini berarti tingkat pendidikan dengan motivasi mempunyai hubungan yang erat.

Pada Tabel 4 dapat dilihat bahwa motivasi yang tinggi dalam menanam kayu bawang dimiliki responden yang berpendidikan rendah. Motivasi tinggi ditandai dengan tujuan menanam sebagai investasi atau alasan komersial. Pendidikan formal yang rendah tidak membuat masyarakat statis. Masyarakat cepat belajar dari pengalaman dan dinamika kehidupan sehari-hari sebagai petani. Pendapatan dari hasil penjualan kayu bawang yang ditanam oleh orang tua mereka dianggap dapat merubah keadaan ekonomi rumah tangga secara drastis, meskipun umumnya berlangsung sesaat. Karenanya, jika ingin mengubah ekonomi rumah tangga saat ini, mereka beranggapan bahwa pembudidayaan kayu bawang dianggap sebagai solusi.

Responden yang memiliki motivasi sedang umumnya mengganggap pohon atau tegakan kayu bawang sebagai tabungan untuk penyiapan kebutuhan bahan bangunan bagi pribadi atau keluarganya. Golongan ini didominasi oleh responden yang berpendidikan menengah dan tinggi. Dalam kasus ini dapat dikatakan bahwa semakin tinggi pendidikan keinginan untuk menanam kayu bawang sebagai cadangan kebutuhan kayu semakin besar.

Informasi ini menunjukkan bahwa masyarakat yang berpendidikan rendah memiliki motivasi tinggi dalam membudidayakan pohon kayu pertukangan apabila mereka telah dapat membuktikan sendiri atau mendapatkan informasi dari orang yang dikenal dekat (misalnya karena hubungan kekeluargaan atau bertetangga) tentang perolehan keuntungan finansial yang didapat dari usaha itu. Fakta ini sejalan dengan hasil penelitian Martin dan Winarno (2004) yang menyebutkan bahwa pembudidayaan jati secara komersial di Kabupaten Kaur, Provinsi Bengkulu pada era "booming jati" tahun 1998 sampai 2002 dilakukan oleh orang- 
berpendidikan menengah dan tinggi, sementara petani yang berpendidikan rendah tidak termotivasi untuk ikut menanam. Ini terjadi karena jati bukan merupakan komoditas tradisional setempat, namun lebih dikenal karena faktor gencarnya promosi usaha.

Menurut Barrett et al. (2002) dalam Mercer (2004), pendidikan dan pengalaman petani berperan penting dalam adopsi sistem agroforestri dibanding pertanian konvensional. Sistem agroforestri yang menggunakan komoditas tanaman berkayu (woody perennial plant) membutuhkan pengetahuan dan pengalaman yang lebih baik jika dibanding usaha pertanian biasa. Predo (2003) dalam penelitiannya tentang motivasi petani menanami padang alang-alang dengan pepohonan di Filipina menunjukkan bahwa pendidikan merupakan salah satu karakteristik rumah tangga yang berhubungan erat dengan keinginan petani mengusahakan lahan alang-alang menjadi areal budidaya pepohonan. Namun dalam kasus penanaman kayu bawang oleh masyarakat Bengkulu Utara ini, pengalaman keberhasilan orang tua atau keluarga dekat dalam menanam dan memanen kayu bawang menjadi faktor utama tingginya motivasi responden yang berpendidikan rendah. Menanam kayu bawang dalam kasus masyarakat ini tidak membutuhkan kapasitas pengetahuan dan pendidikan formal yang tinggi.

\section{C.4. Pendapatan dan tingkat motivasi}

Hipotesis yang diuji adalah (Ho) tingkat pendapatan keluarga responden tidak berkaitan dengan tingkat motivasi dalam menanam kayu bawang. Tabel 5 berikut merupakan tabulasi silang antara pendapatan responden dengan tingkat motivasi mereka dalam menanam kayu bawang.

Tabel 5. Keterkaitan antara tingkat pendapatan responden dengan tingkat motivasi dalam menanam kayu bawang

Table 5. The linkage between income level of respondent and motivation level in plantation of kayubawang

\begin{tabular}{|c|c|c|c|c|c|c|c|c|c|c|}
\hline \multirow{3}{*}{$\begin{array}{c}\text { Motivasi } \\
\text { (Motivation) }\end{array}$} & \multicolumn{8}{|c|}{ Tingkat pendapatan (Imone level) } & \multirow{2}{*}{\multicolumn{2}{|c|}{$\begin{array}{l}\text { Jumlah } \\
\text { (Total) }\end{array}$}} \\
\hline & \multicolumn{2}{|c|}{$<500$ ribu } & \multicolumn{2}{|c|}{$\begin{array}{l}500 \text { ribu s.d. } \\
1 \text { juta }\end{array}$} & \multicolumn{2}{|c|}{$\begin{array}{l}1 \text { juta s.d. } \\
2 \text { juta }\end{array}$} & \multicolumn{2}{|c|}{$>2$ juta } & & \\
\hline & $\mathrm{N}$ & $\%$ & $\mathrm{~N}$ & $\%$ & $\mathrm{~N}$ & $\%$ & $\mathrm{~N}$ & $\%$ & $\mathrm{~N}$ & $\%$ \\
\hline Tinggi (High) & 2 & 7,69 & 12 & 24,0 & 3 & 11,5 & 3 & 25,0 & 20 & 17,54 \\
\hline Sedang (Medium) & 20 & 76,9 & 38 & 76,0 & 21 & 80,7 & 9 & 75,0 & 88 & 77,19 \\
\hline Rendah (Low) & 4 & 15,3 & 0 & - & 2 & 7,69 & 0 & - & 6 & 5,26 \\
\hline Jumlah (Total) & 26 & 100 & 50 & 100 & 26 & 100 & 12 & 100 & 114 & 100 \\
\hline
\end{tabular}

Keterangan (Remarks) : N = jumlah responden (total of respondents) 
Hasil analisis chi square $\left(\chi^{2}\right)$ terhadap Tabel 5 sebesar 12,22. Dibandingkan nilai $\chi^{2}$ tabel pada derajat bebas 6 dan taraf nyata $99 \%$ sebesar 16,81, maka $\chi^{2}$ hitung lebih kecil dari ${ }^{2}$ tabel atau hipotesis nol diterima. Artinya, pendapatan responden tidak saling berkaitan dengan motivasi dalam menanam kayu bawang.

Usaha pembudidayaan kayu bawang oleh masyarakat di Bengkulu Utara tidak membutuhkan modal finansial. Sistem agroforestri memungkinkan penanaman komoditas kayu bawang dibudidayakan di antara tanaman pertanian (cash crop) dan dikerjakan pada saat luang. Bibit kayu bawang umumnya diperoleh petani secara gratis dari anakan alam yang banyak tersebar di bawah pohon induk di sekitar desa, meskipun pohon tersebut bukan miliknya. Kayu bawang juga tidak memerlukan persyaratan perawatan yang intensif. Tajuk pohonnya yang sempit memungkinkan tanaman ini dapat berasosiasi dengan tanaman pertanian sampai umur kurang lebih lima tahun. Ketika petani merawat tanaman pertanian (pembersihan gulma) berarti merawat pula kayu bawangnya. Oleh karena itu besar kecilnya pendapatan atau penghasilan seorang responden tidak memengaruhi motivasi dalam membudidayakan kayu bawang.

Masyarakat pembudidaya kayu bawang yang tergolong miskin (penghasilan tidak lebih dari Rp. 1 juta per bulan) umumnya memiliki motivasi dalam kategori sedang sampai tinggi. Bagi mereka menanam kayu bawang merupakan kesempatan mendapatkan hasil kayu guna membangun rumah dan sebagai tabungan (aset) untuk menutupi keperluan finansial besar pada masa-masa tertentu (menikahkan anak, biaya sekolah anak, kecelakaan atau bencana alam). Hasil penelitian ini menguatkan pendapat dan hasil penelitian Chambers dan Leach (1989) yang menyebutkan bahwa pembudidayaan pohon untuk pemanfaatan langsung dan juga untuk dijual merupakan situasi yang mendukung berkembangnya praktik-praktik pembudidayaan pohon oleh masyarakat miskin di pedesaaan.

Hasil penelitian Shackleton et al. (2008) di wilayah pedesaan Afrika Selatan menunjukkan bahwa pendapatan petani berkorelasi positif dengan jumlah jenis yang ditanam dalam satu unit kebun pekarangan. Penelitian tersebut menunjukkan hubungan antara pendapatan petani dengan kemampuannya untuk menanam lebih beragam jenis tanaman. Hanya saja kebun pekarangan bagi masyarakat pedesaan Afrika Selatan dalam penelitian tersebut bukan merupakan sumber pendapatan (income generating). Dalam kasus budidaya kayu bawang di Bengkulu Utara, petani tetap mengharapkan kebun kayu bawangnya sebagai sumber pendapatan dan aset masa depan untuk memperbaiki taraf hidup keluarganya.

\section{KESIMPULAN DAN SARAN}

\section{A. Kesimpulan}

Penelitian ini telah menunjukkan bahwa masyarakat di Bengkulu Utara memiliki motivasi sedang hingga tinggi dalam membudidayakan kayu bawang, jenis pohon penghasil kayu pertukangan di lahan milik. Motivasi sedang hingga tinggi dicirikan oleh tujuan menanam atas alasan komersial, pemenuhan kebutuhan bahan bangunan, berkeyakinan menguntungkan, dan akan terus menanam pada masa mendatang.

Masyarakat yang memiliki motivasi tinggi adalah yang mempunyai lahan garapan cukup luas (lebih dari 1 ha) dan berpendidikan rendah. Ini menunjukkan bahwa kayu bawang diminati oleh yang memiliki lahan usaha tani yang memungkinkan pengaturan ruang bagi kayu bawang dan komoditas pertanian lain, baik secara bersamaan maupun terpisah. 
Masyarakat yang berpendidikan formal rendah cenderung menyukai dan mempertahankan tradisi membudidayakan jenis pohon penghasil kayu pertukangan apabila mereka telah merasakan sendiri aspek kemanfaatan hasil usaha tersebut.

\section{B. Saran}

Program pengembangan hutan rakyat yang berbasis jenis pohon penghasil kayu pertukangan hendaklah memahami bagaimana diterimanya jenis tersebut oleh kelompok masyarakat menjadi sebuah tradisi. Pohon penghasil kayu pertukangan akan diterima dan dikembangkan dengan baik apabila masyarakat (petani) memiliki lahan usaha tani yang memungkinkan berasosiasinya beragam jenis tanaman dan mereka dapat merasakan sendiri keuntungan akan usaha tersebut. Penyuluhan sesama petani (peer teaching) dapat menjadi alternatif dalam mengembangkan komoditas seperti ini.

Fokus penelitian lanjutan yang perlu dilakukan untuk memperkuat hasil penelitian ini adalah menganalisis bagaimana faktor-faktor di luar karakteristik rumah tangga memengaruhi keputusan rumah tangga dalam mempertahankan dan mengembangkan tradisi menanam kayu bawang. Faktor-faktor tersebut misalnya, perubahan orientasi pasar (preferensi komoditas), apresiasi komunitas luar terhadap tradisi ini (trend permintaan kayu), peran pemerintah dan masyarakat sipil.

\section{DAFTAR PUSTAKA}

Anwar, G., Gunsiryadi, Amrina. 1999. Prospek pengembangan kayu wawang (Protium javanicum Burm F.) Sebagai komoditas hutan unggulan dalam pengusahaan hutan rakyat di provinsi Bengkulu (tinjauan dari aspek silvikultur). Prosiding Seminar Nasional Status Silvikultur: Peluang dan Tantangan menuju Produktivitas dan Kelestarian Sumberdaya Hutan Jangka Panjang. Fakultas Kehutanan Universitas Gadjah Mada.

Chambers R., M. Leach. 1989. Trees as saving and security for the rural poor. World Development 17(3):329-342.

Daniel, W.N. 1989. Statistika Non Parametrik Terapan. PT. Gramedia: Jakarta.

David S. 1997. Household economy and traditional agroforestry systems in western Kenya. Agriculture and Human Values, 14: 169-179.

Dede, 1998. Pengelolaan hutan rakyat kemenyan (Styrax sp.) dan kontribusinya terhadap pendapatan rumahtangga (Kasus di Desa Simasom dan Desa Sosor Tombok, Kabupaten Tapanuli Utara). Di dalam Suharjito D. dan D. Darusman, penyunting. Kehutanan Masyarakat Beragam Pola Partisipasi Masyarakat dalam Pengelolaan Hutan. Institut Pertanian Bogor dan Ford Foundation: Bogor.

De Foresta, H., A. Kusworo, G. Michon dan W.A. Djatmiko, editor. 2000. Ketika kebun berupa hutan: Agroforest Khas Indonesia Sebuah sumbangan masyarakat International Centre For Research in Agroforestry. Bogor. 
Dinas Kehutanan Kabupaten Bengkulu Utara. 2004. Budidaya Kayu Bawang. Dinas Kehutanan Kabupaten Bengkulu Utara: Arga Makmur.

Gouyon A., H. de Foresta, P. Levang. Does 'jungle rubber' deserve its name? An analysis of rubber agroforestry systems in Southeast Sumatra. Agroforestry Systems, 22 : 181 206.

Kartasubrata, J. 2003. Social Forestry dan Agroforestry di Asia. Buku I. Lab. Politik Ekonomi dan Sosial Kehutanan Fakultas Kehutanan Institut Pertanian Bogor.

Martin E., A. Sofyan, M. Ulfa dan A. Nopriansyah. 2002. Teknologi dan Kelembagaan Pengembangan Hutan Rakyat di Provinsi Sumatera Selatan. Laporan Penelitian Balai Litbang Hutan Tanaman Indonesia Bagian Barat, Palembang. Tidak dipublikasikan.

Martin E., M. Ulfa, A. Silalahi, B. Winarno, 2003. Agroforestry tradisional sebagai basis pengembangan hutan rakyat. Prosiding Ekspose Hasil-Hasil Penelitian UPT Badan Litbang Kehutanan wilayah Indonesia Barat. Puslitbang Bioteknologi dan Pemuliaan Tanaman Hutan. Yogyakarta.

Martin E., B. Winarno. 2004. Potensi dan hambatan pembudidayaan jati rakyat di Kabupaten Kaur Bengkulu. Forum Komunikasi Jati, Yogyakarta, 24 September 2004.

Mercer D.E. 2004. Adoption of agroforestry innovations in the tropics: A review. Agroforestry Systems 204411:311-328.

Michon G., F. Mary and J. Bompard. 1986. Multistoried agroforestry system garden system in West Sumatra, Indonesia. Agroforestry Systems 4(4): 315-338.

Montambault J.R. dan J.R.R. Alavalapati. 2005. Socioeconomic research in agroforestry: a decade in review. Agroforestry Systems 32:247-260.

Pattanayak S., D.E. Mercer, E. Sills, and J. Yang. 2003. Taking stock of agroforestry adoption studies. Agroforestry Systems 57:173-186.

Predo C.D. 2003. What Motivates Farmers? Tree Growing and Landuse Decision in the Grassland of Claveria, Philippines. Singapore: the Economy and Environment Program for Southeast Asia (EEPSEA).

Ruf F., S. Taher, dan Yoddang. 2005. Peremajaan tanaman kopi di Sumatra Selatan. Di dalam Ruf F. dan Lançon F., editor. Dari Sistem Tebas dan Bakar ke Peremajaan Kembali. Revolusi Hijau di Dataran Tinggi Indoensia. Salemba Empat: Jakarta.

Salam M.A., T. Noguchi, and M. Koke. 2000. Understanding why farmers plant trees in the homestead agroforestry in Bangladesh. Agroforestry Systems, 50: 77-93.

Shackleton C.M., F. Paumgarten, M.L. Cocks. 2008. Household attributes promote diversity of tree holdings in rural areas, South Africa. Agroforest Syst, 72:221-230.

Sood K.K. dan C.P. Mitchell. 2004. Do socio-psychological factors matter in agroforestry planning? Lessons from smallholder traditional agroforestry systems. Small-scale Forest Economic, Management and Policy, 3(2):239-255. 
Suharjito D, L. Sundawati, Suyanto, S.R. Utami. 2003. Aspek Sosial Ekonomi dan Budaya Agroforestri. Bahan Ajaran Agroforestri 5. World Agroforestry Centre (ICRAF): Bogor.

Suyanto S., T.P. Tomich, and Otsuka K. 2001. Land tenure and farm management efficiency: The case of smallholder rubber production in costumary land areas of Sumatra. Agroforestry System, 52:145 160.

Torquebiau E. 1984. Man-made dipterocarp forest in Sumatra. Agrofor Syst 2:103-127.

Torquebiau E. dan E. Penot. 2006. Ecology versus economics in tropical multistrata agroforests. Kumar B.M. dan P.K.R. Nair (Editor), Tropical Homegardens: A TimeTested Example of Sustainable Agroforestry: 269-282. Netherlands: Springer.

Wijayanto N. 2002. Kontribusi repong damar terhadap ekonomi regional dan distribusi pendapatan. Jurnal Manajemen Hutan Tropika, 7(2): 1-9. 